\title{
VENUSS rising for papillary renal cell carcinoma prognostication?
}

\author{
Tomas Buchler \\ Department of Oncology, First Faculty of Medicine, Charles University and Thomayer Hospital, Prague, Czech Republic \\ Correspondence to: Tomas Buchler. Department of Oncology, First Faculty of Medicine, Charles University and Thomayer Hospital, Videnska 800, \\ 14059 Prague, Czech Republic. Email: tomas.buchler@ftn.cz. \\ Provenance and Peer Review: This article was commissioned and reviewed by the Section Editor Dr. Xiao Li (Department of Urology, Jiangsu Cancer \\ Hospital, Jiangsu Institute of Cancer Research, Nanjing Medical University Affiliated Cancer Hospital, Nanjing, China). \\ Comment on: Klatte T, Gallagher KM, Afferi L, et al. The VENUSS prognostic model to predict disease recurrence following surgery for non- \\ metastatic papillary renal cell carcinoma: development and evaluation using the ASSURE prospective clinical trial cohort. BMC Med 2019;17:182.
}

Submitted Mar 17, 2020. Accepted for publication Apr 14, 2020.

doi: 10.21037/atm.2020.03.216

View this article at: http://dx.doi.org/10.21037/atm.2020.03.216

Prognostic scores have been developer for various cancers to provide a tool for patient stratification. Ultimately the application of a successful prognostic score should help the physician to plant he follow-up and decide on the use of adjuvant therapies.

Several prognostic systems have been proposed for patients with renal cell carcinoma (RCC). For resected localised or locoregional disease, the most widespread ones include the Stage, Size, Grade, and Necrosis (SSIGN), the University of California Los Angeles integrated staging system (UISS), and the Leibovich score (1-3). All the above models for prognostication of port-operative survival for non-metastatic RCC are based on the TNM classification and evaluation of the tumour grade.

The novel Venous Extension, Nuclear grade, Size, Stage (VENUSS) prognostic system proposed by Klatte et al. has been designed to predict recurrence risk for patients with resected stage I-III papillary renal cell carcinoma PRCC (4). The model groups patients into three risk groups based on 11 parameters that include $\mathrm{pT}$ stage, tumour size (pTa or pTb), $\mathrm{N}$ stage, nuclear grade determined using the new International Society of Urological Pathology (ISUP) grading system (5), and the presence/absence of the venous thrombus. The model was developed on a database of 556 patients and validated in 150 patients treated with adjuvant tyrosinkinase inhibitors in the ASSURE trial (Sunitinib Malate or Sorafenib Tosylate in Treating Patients with Kidney Cancer That Was Removed by Surgery, NCT00326898). Full results of this trial have been published and no benefit of the adjuvant treatment was observed for the "other histology" subgroup of 267 patients that included the above cohort of PRCC patients (6).

PRCC is the second most common type of RCC accounting for approximately $15 \%$ of patients. Type 1 PRCC appears to be a fairly homogeneous entity exhibiting characteristic copy-number variation patterns with frequent polysomy of chromosomes 7 or 17 . In contrast, type 2 PRCC does not possess generalizable molecular characteristics (7). Hereditary papillary RCC often carries MET mutations, a therapeutic target (7). This heterogeneity of the diagnosis of PRCC presents another caveat for the new prognostic system, which may rapidly become obsolete as molecular-based classifications replace the histological ones.

In the absence of any proven adjuvant therapy for PRCC, in the near future the VENUSS score may be more applicable for the design of follow-up surveillance programmes. At the moment, guidelines for long-term post-operative follow-up are based on expert opinion and direct evidence for their impact on patient survival is lacking. Furthermore, RCC is notorious for extremely late recurrences. In an analysis of 3,651 patients by Stewart et al., the procedures prescribed by various US follow-up recommendations capture $25-68 \%$ of recurrences. Sharply increased costs would result from prolonged and more intensive programmes that would theoretically detect up to $95 \%$ of recurrences in patients with resected RCC (8). In patients who are elderly or with significant comorbidity, the risk of non-cancer death rapidly outstrips that of RCC-related death (9). With these analyses in mind, it is 
interesting that the risk of abdominal recurrences in the VENUSS cohort of PRCC patients was relatively flat after year two post-surgery. Almost all recurrences in the highrisk group developed in the first 2 years after surgery. The cumulative recurrence risk after 5 years was only $2.9 \%$ in patients allocated to the low risk group by VENUSS score. While the steadily increasing albeit moderate cumulative incidence of relapses in the intermediate-prognosis group is challenging to address in a surveillance plan, the data suggest that restaging by imaging could perhaps be reduced in high-risk patients surviving 2 years without relapse and in low-risk patients.

The VENUSS study has been criticised for its grouping of patients with relatively variable prognostic outlooks and not providing detailed data that would permit the calculation of individual risk by Tan and Assel (10), citing the TRIPOD guidelines (11). However, from the clinical perspective this argument seems less relevant. As there are no established adjuvant therapies for RCC, let alone for PRCC, a validated risk grouping is both useful and necessary for designing clinical trials at the current state of knowledge. Given the natural course of the disease in PRCC patients, these trials will inevitably concentrate on patients in the high-risk groups if any interpretable results are to be achieved in a reasonable time-frame.

Finally, novel molecular panels may in the near future replace the prognostic models based on clinical and morphological parameters. In 2015, Rini and collaborators have published the results of their analysis of a 16-gene assay for clear-cell RCC. The multigene assay has been found to be superior to conventional prognostic models in a cohort of 942 patents with stage I to II RCC. The additional potential benefit of similar genetic models may be the identification of targetable molecular abnormalities that could be used to select targeted treatment should the cancer recur (12).

\section{Acknowledgments}

Funding: None.

\section{Footnote}

Conflicts of Interest: The author has completed the ICMJE uniform disclosure form (available at http://dx.doi. org/10.21037/atm.2020.03.216). TB reports grants and personal fees from Novartis, grants and personal fees from Roche, personal fees from Pfizer, grants and personal fees from Bristol Myers Squibb, personal fees from Ipsen, grants from Bayer, outside the submitted work.

Ethical Statement: The author is accountable for all aspects of the work in ensuring that questions related to the accuracy or integrity of any part of the work are appropriately investigated and resolved.

Open Access Statement: This is an Open Access article distributed in accordance with the Creative Commons Attribution-NonCommercial-NoDerivs 4.0 International License (CC BY-NC-ND 4.0), which permits the noncommercial replication and distribution of the article with the strict proviso that no changes or edits are made and the original work is properly cited (including links to both the formal publication through the relevant DOI and the license). See: https://creativecommons.org/licenses/by-nc-nd/4.0/.

\section{References}

1. Frank I, Blute ML, Cheville JC, et al. An outcome prediction model for patients with clear cell renal cell carcinoma treated with radical nephrectomy based on tumor stage, size, grade and necrosis: the SSIGN score. J Urol 2002;168:2395-400.

2. Zisman A, Pantuck AJ, Dorey F, et al. Improved prognostication of renal cell carcinoma using an integrated staging system. J Clin Oncol 2001;19:1649-57.

3. Leibovich BC, Blute ML, Cheville JC, et al. Prediction of progression after radical nephrectomy for patients with clear cell renal cell carcinoma: a stratification tool for prospective clinical trials. Cancer 2003;97:1663-71.

4. Klatte T, Gallagher KM, Afferi L, et al. The VENUSS prognostic model to predict disease recurrence following surgery for non-metastatic papillary renal cell carcinoma: development and evaluation using the ASSURE prospective clinical trial cohort. BMC Med 2019;17:182.

5. Delahunt B, Cheville JC, Martignoni G, et al. The International Society of Urological Pathology (ISUP) grading system for renal cell carcinoma and other prognostic parameters. Am J Surg Pathol 2013;37:1490-504.

6. Haas NB, Manola J, Uzzo RG, et al. Adjuvant sunitinib or sorafenib for high-risk, non-metastatic renal-cell carcinoma (ECOG-ACRIN E2805): a double-blind, placebo-controlled, randomised, phase 3 trial. Lancet 2016;387:2008-16.

7. Alaghehbandan R, Perez Montiel D, Luis AS, et al. 
Molecular Genetics of Renal Cell Tumors: A Practical Diagnostic Approach. Cancers (Basel) 2019;12:8.

8. Stewart SB, Thompson RH, Psutka SP, et al. Evaluation of the National Comprehensive Cancer Network and American Urological Association renal cell carcinoma surveillance guidelines. J Clin Oncol 2014;32:4059-65.

9. Stewart-Merrill SB, Thompson RH, Boorjian SA, et al. Oncologic Surveillance After Surgical Resection for Renal Cell Carcinoma: A Novel Risk-Based Approach. J Clin Oncol 2015;33:4151-7.

Cite this article as: Buchler T. VENUSS rising for papillary renal cell carcinoma prognostication? Ann Transl Med 2020;8(16):1036. doi: 10.21037/atm.2020.03.216
10. Tan KS, Assel M. The use and drawbacks of risk-grouping in prediction models. BMC Med 2020;18:10.

11. Collins GS, Reitsma JB, Altman DG, et al. Transparent reporting of a multivariable prediction model for individual prognosis or diagnosis (TRIPOD): the TRIPOD statement. BMJ 2015;350:g7594.

12. Rini B, Goddard A, Knezevic D, et al. A 16-gene assay to predict recurrence after surgery in localised renal cell carcinoma: development and validation studies. Lancet Oncol 2015;16:676-85. 